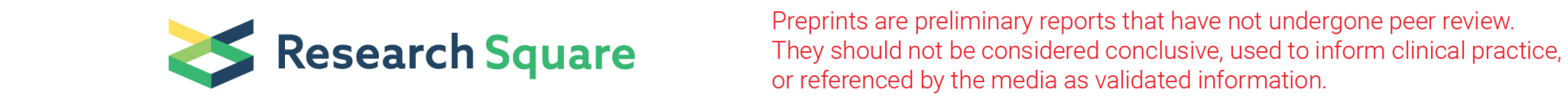

\title{
Quality of Life after Motorcycle Traffic Injuries: A Cohort Study in Northwest of Iran
}

\author{
Leili Abedi Gheshlaghi \\ Kerman University of Medical Sciences \\ Hamid Sharifi ( $\sim$ sharifihami@gmail.com ) \\ Mehdi Noroozi \\ Mohsen Barouni \\ Kerman University of Medical Sciences \\ Homayoun Sadeghi-bazargan \\ Tabriz University of Medical Sciences
}

\section{Research article}

Keywords: Quality of life, motorcycle traffic injuries, cohort study, Iran

Posted Date: April 15th, 2020

DOI: https://doi.org/10.21203/rs.3.rs-15569/v2

License: @) (i) This work is licensed under a Creative Commons Attribution 4.0 International License. Read Full License 


\section{Abstract}

Background: The number of studies to address the Quality of life (QOL) after a motorcycle accident in the context of developing countries is low. In this study, we investigated the QOL of injured motorcyclists up to three months after their accident and determining the associated factors.

Methods: In the present study, we included 190 injured motorcyclists who admitted at two referral specialized hospitals (Emam Reza and Shohada) in Tabriz, between June 2018 and January 2019, and agreed to participate. All injured motorcyclists were contacted through the telephone one and 171 of them (90\%) three months after their accident to complete an EQ-5D-3L questionnaire. The baseline measurements were gathered by using face to face interviews in the hospitals. The QOL score could vary between 1-3. The higher score showed a lower QOL. The Generalized Estimating Equation (GEE) models were used to determine the factors affecting the motorcyclists' QOL.

Results: The injured motorcyclist's QOL was relatively better three months after the accident (mean \pm Standard Deviation: $2.15 \pm 0.65$ ) in comparison with their status a month after the accident (mean \pm SD: $1.78 \pm 0.51)(p<0.001)$. The multivariable model showed that individuals whose pelvis (Coef: 0.29, (95\% Confidence Intervals [Cl]: 0.16, 0.42), P= 0.001) and knee (Coef: $0.26,(95 \% \mathrm{Cl}: 0.10,0.42), P=0.001)$ were injured, experienced a lower QOL. Also, those whose accident had happened in rainy weather experienced lower QOL (Coef: $0.33,(95 \% \mathrm{Cl}: 0.12,0.53), \mathrm{P}=$ 0.001). Those who were in an accident with a vehicle experienced a better QOL than others (Coef: $-0.26,(95 \% \mathrm{Cl}:-0.43,-0.09), P=0.002)$.

Conclusion: The assessment of three-month post-discharge showed that the QOL of the motorcyclists was better. It is recommended that by designing multi-year cohort studies, the QOL of motorcyclists be assessed for a longer time to identify the practical factors that improve the QOL of injured motorcyclists. In hospital discharge victims (especially for those with lower limb injuries such as injury to pelvis and knee, victims with Post-traumatic stress disorder, depression, and anxiety problems), social support, psychological support, financial support, and rehabilitation should be considered to improve the QOL.

\section{Background}

According to the World Health Organization (WHO) report, 1.35 million individuals are killed due to Road Traffic Injuries (RTIs), and more than 50 million are injured or disabled each year $(1,2)$. Thus, premature death and disability with long-term consequences impose a considerable burden on people and society (3). The effects of non-fatal injuries include both the physical aspect of the RTIs and the psychosocial factors following the injury. The physical consequences of injuries have received much more academic attention, while the psychological aspects have been neglected (4). Therefore, the QOL of the survivors of accidents is a critical issue to be assessed and addressed (5).

Studies conducted on the QOL have shown that this concept has a multidimensional structure including physical, psychological and social. (6). According to WHO guidelines, QOL is a subjective and dynamic concept determined by affected people and not by any other person; it changes dynamically over time and thus should be measured within a specified period (7).

A considerable volume of literature exists on the QOL of the victims of RTIs (8-13). The results of a prospective cohort study in France assessing the QOL of the victims of RTI through one-year follow-up showed that head injury, severe injury, intention to complain, early post-accident medical complications were predictive of health dissatisfaction. Moreover, post-traumatic stress disorder (PTSD), socioeconomic problems are believed to be associated with poor QOL (14). A prospective cohort study in Germany assessing the health-related quality of life two years after a traumatic experience of severely injured patients showed that more than $60 \%$ of them reported relevant persistent pain and severe functional deficit in at least one body region (15). Moreover, several longitudinal cohort studies showed that individuals who suffered injuries following RTIs reported long-term life consequences (such as physical, psychological, financial, and everyday life consequences) and there were psychological reactions like travel anxiety and symptoms like PTSD, which were reported more by women. Therefore, women, compared with men, have poorer QOL. Moreover, psychological reactions such as PTSD and QOL have been reported in victims after RTIs (16-18).

In comparison with other vehicle users, motorcyclists suffer from more severe and multiple injuries, especially to the arm and adjacent area. Most motorcyclists had a poor health status about three years after the accident; also, the rate of anxiety and fear of traveling was the highest in riders and passengers (19). The QOL of injured motorcyclists of accidents are conducted much less especially in developing area and in the context of Iran. Therefore, the aim of this study was to investigate the QOL of injured motorcyclists and associated factors in a period of three months after the accident.

\section{Method}

The present study is a part of the Persian Traffic Cohort (PTC) study, and cases were selected from the Iranian Integrated Road Traffic Injury Registry (IRTIR) system used in it. The Ministry of Health and Medical Education designed IRTIR with the collaboration of WHO. The comprehensive IRTIR system has been established in Emam Reza and Shohada hospitals as the two referral specialty centers in the Eastern Azarbaijan Province, Iran. The IRTIR gathers data at several sections as follows: crash scene section, emergency section, hospital admission section, forensic medicine section, and post-discharge section. 
We recruited 190 injured motorcyclists admitted to the two referral specialty hospitals of Emam Reza and Shohada in Tabriz from June 2018 to January 2019 willing to participate in this study were enrolled. Among them, we could contact 171 injured people three months after the accident. The inclusion criteria were as follows:

1) Being involved in traffic injury (according to the United Nations Economic Commission for Europe (UNECE) definition (20), "road traffic accidents are those accidents:

a) Which occurred or originated on a way or street open to public traffic

b) Which resulted in one or more persons being killed or injured

c) In which at least one moving vehicle was involved."

2) Being a rider or pillion passenger of motorcycle involved in traffic crash accordance with V20-V29 and V31 from International Classification of Diseases-10th revision (ICD-10)

3) Having registered integrated road traffic injuries (hospitalization in trauma centres)

4) Having the participant's consent for inclusion in the study

5) Being lucid, conscious and cooperative during the telephone follow up

Those injured individuals who either were in a coma during the phone follow up or could not talk due to severe pain were excluded.

\subsection{Data collection}

For each injured motorcyclist (both the rider and the passenger 'if applicable') admitted to the hospitals (Emam Reza and Shohada), baseline measurement was collected through a face-to-face interview at the hospital admission section of IRTIR through data collection tool in the nursing station.

\section{- Baseline measurement}

The following information was gathered using a face-to-face interview at the hospitals:

1) Demographic characteristics (the name of the hospital where they had been admitted, admission date, case number, national ID number, age, sex, nationality, level of education, marital status, job, address, landline number, cellphone number, cellphone number of next of kin or anyone who could be contacted after the admitted individual was released from the hospital).

2) Crash related variables including:

1. a) Information regarding the time and location of the accident (such as the day, month, and year of the accident, the exact day of the week, the time of the accident, whether light status (daytime, nighttime), the weather condition, road condition at the time of the accident and whether it was slippery, whether the accident occurred in the city or in the suburbs).

2. b) Information regarding the vehicle (including the number of vehicles involved in the accident, the type of vehicle involved in the accident and the mechanism of accident (e.g., vehicle-fixed object crash, vehicle-vehicle, overturning, vehicle-pedestrian, and vehicle-animal crash)

3. c) Information about the person (including the role of the injured person: whether s/he was the cyclist or the passenger, whether the injured rider had a rider license, whether s/he had the experience of riding a motorcycle, the average time of riding a motorcycle per day, the average number of days the injured motorcyclist rides the motor per week, whether a cellphone was used during riding and if yes whether they were using headphones or they were holding their cellphone in their hand, the motorcyclist communication status with the passenger before the accident, whether the motorcyclists had drunk alcohol and/or had taken drugs). All of these data were recorded in the comprehensive IRTIR system.

3) Information regarding the severity of accident injuries was extracted from the Health Information System (HIS) of the hospitals. The type of injuries was defined according to ICD-10 codes as follows: head injuries (S00-S09), neck injuries (S10-S19), thoracic injuries (S20-S29), injuries to the abdomen, lower back, lumbar spine and pelvis (S30-S39), shoulder and above elbow injuries (S40-S49), elbow and forearm injuries (S50-S59), wrist and hand injuries (S60-S69), leg and pelvis injuries (S70-S79), knee and lower knee injuries (S80-S89), foot and ankle injuries (S90-S99).

\section{- Follow up assessment including QOL}

One and three months after the accidents, injured hospitalized motorcyclists were contacted by telephone for a follow-up. Required information for performing the follow-up was collected from the IRTIR system. The call duration for each person lasted from 5 to 10 minutes. 
The EQ-5D-3L questionnaire was developed in 1987 by a team of researchers from five European countries to assess the QOL. This standard questionnaire covers five aspects of mobility, self-care, usual activities, pain/discomfort, and anxiety/depression. For each of these aspects, the following scale is considered: 1) I have no problem, 2) I have some difficulty, and 3) I have many issues. The overall score is calculated as the sum of the scores obtained from each aspect divided by 5 . The average overall score is between 1 (high QOL) and 3 (low QOL) (21). A higher score shows a bad QOL.

The Iranian socio-economic assessment questionnaire (second brief version) covers six items, including occupation, income per month, years of successful education, private housing, private car, and the share of health expenditure to the total expenditures. To measure the overall score, questions four, five, and six are multiplied by 0.33 ; then, the sum of the answers to all questions is calculated. To classify the economic-social status to very low, low, medium, and high levels, statistical quartiles of the overall score are used. The validity and reliability of this questionnaire were proved by Dr. Sadeghi et al. (22).

\subsection{Statistical analyses}

Descriptive statistics for normal quantitative, not normal quantitative and qualitative variables have been reported as mean (standard deviation), median (P25-P75), and frequency (percent), respectively. We checked the normality of continuous variables (including age, number of riding days during last week, time of accident occurrence, hospital admission days, and quality of life score) by the Shapiro-Wilk test. Demographic variables, baseline variables, and quality of life score were compared in the first and second follow-ups using the Chi-square test, Mann Whitney, and independent t-tests.

In the present study, our data was longitudinal and the Generalized Estimating Equations GEE model is recommended more for longitudinal data that could manage the correlation between multiple measurement (23). So, Bivariable and multivariable linear models of the GEE with unstructured variance-covariance matrix were used to determine the factors affecting the QOL of injured motorcyclists. In this model, the QOL score was the dependent variable, and the baseline variables were considered as independent variables. In the bivariable model, we entered all demographic variables (included age, sex, level of education, marital status, and job) and baseline variables to the model. Therefore, we tested the association of these variables with the QOL score. In the multivariable GEE model, the variables that with a p-value <0.1 $(24)$ in the bivariable were included in the model. The backward elimination, using Wald test, was used to reduce the model. In all analyses, a p-value $<0.05$ was considered statistically significant. Stata SE software (Version 13) was used for data analysis.

This study has been approved by the Ethics Committee of Kerman University of Medical Sciences (Ethics code: IR.KMU.REC.1397.141) and carried out under the national ethical codes for the primary cohort and registry. Also, verbal consent was received from all participants before enrollment.

\section{Results}

\subsection{Basic measurement}

The mean \pm standard deviation (SD) age of the participants was $29.65 \pm 14.02$; more than sixty percent of them had an education level higher than six classes. Five (2.6\%) injured participants were women, and 103 (53.7\%) were single. Eighty-five percent of the injured participants were riders, and only 37 (19.8\%) individuals were wearing helmets at the time of the accident. More than half of the injured motorcyclists had over ten years of experience of riding and rode the motorcycles for one to four hours during the week. Two-thirds of injured riders did not have a rider's license. Totally, 173 (92\%) accidents occurred on sunny days, and only 11 (5.8\%) roads were slippery. Most accidents occurred on the main roads in the city, while 59 (72.8\%) accidents that happened out of town were on side roads (Table 1).

\subsection{Quality of life}

The mean \pm SD score of the QOL of injured motorcyclists in the first month after the accident was $2.15 \pm 0.65$, and it was $1.78 \pm 0.51$ in the three months after the accident. The QOL score within the third month of their follow-up was better than the first month after the accident ( $P<0.001)$ (Table 1). The mean score of QOL was higher in the hip, knee, and thorax injuries.

Moreover, the 21-35 year age group had the highest QOL score. The mean score of QOL is low in no rainy weather, one vehicle involved in an accident, and being the passenger. But the mean score of QOL in main road accidents comparison to by road accident did not have different (Figure 1).

\subsection{Predictors of QOL}

In bivariable analysis by GEE linear, the following factors about the type of occurred accident affect the QOL of the injured individuals: being in rainy days (Coef: $0.45, P=0.001)$, no vehicle involved (Coef: $-0.42, P=0.001)$, motorcycle overturn (Coef: $-0.54, P=0.001)$, one vehicle involved in the accident (Coef: $-0.39, P=0.001)$, being the passenger (Coef: $-0.13, P=0.03$ ) and), knee injuries (Coef: $0.34, P=0.001)$, pelvis injuries (Coef: $0.30, P=0.001)$. However, the QOL score was not statistically associated with age, sex, marital status, outside city crashes, intercity crashes, day of the accident, time of accident, lighting intensity during the accident, a slippery condition during the accident, accidents happening during a 
holiday, having a riding license, average riding hours per day, riding history of rider, the number of riding days during last week, rider conversation with passenger, helmet use, job, and education level.

In the final model, we had five variables, including the role of injured persons, hip and thigh injuries, knee and lower leg injuries, the number of vehicles involved in the accident, weather conditions during accidents. Based on the final model, those injured individuals whose pelvis (Coef: 0.26 , $P=0.001$ ), and knee (Coef: $0.29, P=0.0001$ ) had been hurt experienced lower QOL than others. Accidents that had occurred on rainy days, in comparison with those that happened on sunny days, reduced the QOL of the injured individuals (Coef: $0.33, P=0.001$ ). Those who were in an accident with a vehicle experienced a better QOL than others (Coef: -0.26, P=0.002) (Table 2).

\section{Discussion}

The results of the present study showed that the QOL of injured motorcyclists was low a month after their accident, which is consistent with the results of a similar study conducted in India (25). Comparing the mean score of the QOL of the participants of this study with the mean score of the QOL of the general population in Australia (26), China (27), and Iran (28) showed that the QOL scores of the general population in Australia (0.9), China (0.98) and Iran (0.74) were significantly higher than the QOL of the injured after one month of follow-up in this study.

Our study showed that QOL of injured people in motorcycle accidents, three months after accident, was partially improved when compared to one month post-accident, and this finding is consistent with the results of a study in Australia (13). Results of a systematic review also showed that there was a decrease in the score of QOL of injured people in accidents immediately after the accident or after their discharge from the hospital. However, most of the injured people experienced an increase in their QOL from six months to eight years after their accident. Nevertheless, they will not reach the public QOL obtained in the last follow-up (six weeks to two years) (18). Only one study that specifically examined the QOL of injured motorcyclists over three months after their accident. This study showed that in comparison with other injured individuals, they continued to require medical care and suffered from severe injuries from three months to a year after their accident (19). Hence, more studies are required on injured motorcyclists to help understand whether the improvement of their QOL is due to their adjustment to the aftermath of the accident or the reduction of their disabilities and the improvement of their symptoms.

Moreover, the negative consequences of road accidents may be reduced by first aid, specialist transport, and emergency treatment of the victims (29). So, in low- and middle-income countries such as Iran, strengthening first aid courses, an accident notification system, and improving the cooperation of rescue services can be sufficient in improving post-accident medical care (30). In these countries, interventions should not only be restricted to pre-accident or hospital but also, after hospital discharge; countries should have serious plans, especially for high-risk groups. Extensive follow-up of patients and victims with low quality of life should be considered after discharge from the hospital. More specifically, it seems necessary to enhance and extend care, social support, psychological support, financial support and rehabilitation for subjects at high risk of not fully recovering, such as very seriously injured victims, those with lower limb injuries such as injury to pelvis and knee and the victim with PTSD. Moreover, early psychological monitoring and counseling are essential for patients who experienced even minor traffic accidents (31). Therefore, successful interventions such as cognitive behavior therapy interventions should be used for patients in emergency departments and post-discharge by healthcare staff. Early identification and subsequent referral to treatment for PTSD, depression, and anxiety may decrease the likelihood of these conditions affecting long term QOL $(18,31)$.

Based on the results of a review (18), the factors affecting the QOL of traffic accident victims are categorized into four groups: 1) demographic variable, 2) clinical variables, 3) psychosocial variables, and 4) socioeconomic variables. Regarding the demographic variables, there was no significant relationship between age or sex and the QOL of the injured participants in the present study. This is consistent with the results of other studies $(11,32)$. Yet, our results were inconsistent with the results of cohort studies conducted in France and Australia where injured adults (usually above 35 years old) had a poorer QOL in comparison with young people (14,33), and comparison with men; women had a poorer QOL (10). Accordingly, from two to eight months after their accident, women tended to return to their job $18 \%$ less than men due to the persistence of their medical issues (34). One of the reasons for the inconsistency between these two studies is the difference in the pattern of RTIs since, in both Australian and French studies, all RTIs were studied, but the present study merely focused on motorcycle accidents. Besides, the difference in the sex distribution of the injured participants in these RTIs is another reason of the inconsistency of results. In Eastern Mediterranean countries, most injured individuals are men; however, in other types of road accidents, as cited in a study conducted in Australia, about $40 \%$ of the injured participants were women. A cohort study in Australia showed that being older and being less hopeful to return to the job were reversely related to physical health-related QOL (35). It is recommended that cohort studies be conducted with a few years of follow-up after the accidents for the motorcyclists in low- and middle-income countries (LMICs) to assess the quality of their life.

Concerning clinical variables, the present study showed that injury to pelvis and knee reduced the QOL, which is in line with the results of studies conducted in Canada and France $(32,34)$. In the present study, no significant relationship was found between the length of hospitalization and the QOL of the injured. The results of a study in Australia, however, showed that staying for one or more nights in a hospital had a negative impact on the QOL of the injured patient, which contradicts the results of the present study. Differences in the target group may be one of the reasons for this inconsistency. In an Australian study (11), patients who were hospitalized for more than seven days and those with severe injuries were excluded; 
yet, in the present study, about $15 \%$ of the injured were hospitalized for more than seven days, and all injuries were included in the study. The hospitalization duration of less than half of the injured participants was not accurately documented.

In the present study, accidents that occurred on rainy days reduced the QOL, but those who were an accident with a vehicle had a better QOL compared to the others. According to the results of previous studies conducted in India and Italy, the severity of accidents on rainy days is higher than sunny days (36). Moreover, compared to car accidents, the severity of injuries from motorcycle accidents is higher (37). Being severely injured reduces the QOL.

In Eastern Mediterranean countries such as Iran, the education program for road users (e.g., promotion campaigns, educational programs, programs training skills for motorcycles and improvement courses for the older rider) may contribute to the change of behaviors of motorists. This could increase the awareness to prevent and reduce the deaths or severe physical injuries of the motorcycle victims. Education should cover the three main risk factors which contribute to road accidents, i.e., speed, alcohol, and not using protective helmets (30). Moreover, designing motorways, the construction of elements of a road infrastructure enforcing speed limits (38), establishment and applying laws to wear a protective helmet, determining standards for motorcycle protection helmets, specific sanctions for not using protective helmet (39) are effective factors to decrease the number of motorcycle accidents. The limitations of this study were: 1) injured individuals with severe injuries and critical conditions were excluded from the study, and 2) some injured individuals did not respond to phone calls in the follow-up process; these limitations could lead to a selection bias.

\section{Conclusion}

The assessment of three-month post-discharge showed that the QOL of the motorcyclists was improved. Since motorcycles are affordable vehicles for people in low- and middle-income countries, and as reported by WHO, more than half of all road traffic fatalities involved motorcyclists, we expect that the results of this study would be a starting point for policy-makers and authorities' extra efforts to improve motorcyclists' safety levels. The following measures are suggested: producing standard and affordable helmets, considering separate routes for motorcyclists on roads, providing more medical and insurance support to motorcyclists in comparison with the users of other vehicles since their incident pattern and disability is different. Moreover, it is suggested that by designing multi-year cohort studies, the QOL of motorcyclists be assessed for a longer time to identify the effective factors that improve the QOL of injured motorcyclists and their passengers after their accident and take appropriate measures accordingly. Moreover, the present follow-up study should be extended for several years to assess the long-term consequences of motorcycle traffic injuries further and expand our knowledge of factors linked with quick recovery. On the other hand, social support, psychological support, financial support, and rehabilitation should be considered to improve their quality of life in hospital discharge victims (especially for those with lower limb injuries such as injury to pelvis and knee, victims with PTSD, depression and anxiety problems).

\section{Declarations}

\section{Ethics approval and consent to participate}

This study has been approved by the Ethics Committee of Kerman University of Medical Sciences (reg. code IR.KMU.REC.1397.141) and carried out under the national ethical codes for the main cohort and registry (IR.KMU.REC.1397.141). Also, admission sections were received written consent from everyone. Moreover, for performing the follow-up with telephone contacts, we received verbal approval from all participants before including in the study.

\section{Consent for publication}

Not applicable

\section{Availability of data and material}

The datasets used and analyzed during the current study are available from the corresponding author on reasonable request

\section{Competing interests}

The authors declare that they have no competing interests.

\section{Funding}

This work was supported by the Kerman University of Medical Sciences (grant number IR.KMU.REC.1397.141).

\section{Authors' contributions}

L.A.G, H.S.B, H.SH, M.B, and M.N designed the study and the computational framework. L.A.G carried out the implementation of data gathering. Both L.A.G and H.S.B analyzed the data, and L.A.G, H. S.B, and H.SH contributed to the interpretation of the results. L.A.G wrote the paper with 
input from all authors. All authors provided critical feedback and helped shape the final manuscript.

\section{Acknowledgments}

We would like to thank all the staff at the Traffic Injuries Prevention Research Center of Tabriz University of Medical Sciences for help with data collection. We are also grateful to all injured patients that were collaborated in this study.

\section{Abbreviations}

RTIs: Road Traffic Injuries

PTC: Persian Traffic Cohort

IRTIR: Iranian Integrated Road Traffic Injury Registry system

QOL: Quality of life

HIS: Health Information System

GEE: Generalized Estimating Equations

Cl: Confidence Interval

\section{References}

1. World Health Organization. Philippines-global status report on road safety 2015 [Internet]. WHO Library Cataloguing-in-Publication Data Global. Switzerland: WHO Library Cataloguing-in-Publication Data; 2015. Available from: (www.who.int/about/licensing/copyright_form/en/index.html)

2. World Health Organization. Global status report on road safety 2018 [Internet]. 2018. Available from: https://www.who.int/violence_injury_prevention/road_safety_status/2018/English-Summary-GSRRS2018.pdf

3. Moergeli H, Wittmann L, Schnyder U. Quality of Life after traumatic injury: a latent trajectory modeling approach. psychother psychosom. 2012 Jul 20;81:305-11.

4. Hasselberg M, Kirsebom M, Bäckström J, Berg H Y, Rissanen R. I did NOT feel like this at all before the accident: do men and women report different health and life consequences of a road traffic injury? Inj Prev. 2018;

5. Sprangers M A G. Disregarding clinical trial-based patient-reported outcomes is unwarranted: Five advances to substantiate the scientific stringency of quality-of-life measurement. Acta Oncol (Madr) [Internet]. 2010;49(2):155-63. Available from: https://doi.org/10.3109/02841860903440288

6. Olschewski M, Schulgen G, Schumacher M, Altman D G. Quality of life assessment in clinical cancer research. Br J Cancer [Internet]. 1994;70(1):1-5. Available from: https://www.ncbi.nlm.nih.gov/pubmed/8018517

7. Nejat S. Quality of life and its measurement. Iran J Epidemiol [Internet]. 2008;4(2):57-62. Available from: http://irje.tums.ac.ir/article-1-146en.html

8. Barnes J, Thomas P. Quality of life outcomes in a hospitalized sample of road users involved in crashes. Annu Proc - Assoc Adv Automot Med. 2006; 2006:253-68.

9. Chaikoolvatana A, Sripech S. Quality of life of road accident head-injured patients after craniotomy. Southeast Asian J Trop Med Public Heal. 2007;38(4):761-8.

10. Hours M, Khati I, Charnay P, Chossegros L, Tardy H, Tournier C, et al. One year after mild injury: Comparison of health status and quality of life between patients with whiplash versus other injuries. J Rheumatol. 2014;41(3):528-38.

11. Jagnoor J, De Wolf A, Nicholas M, Maher C G, Casey P, Blyth F, et al. Restriction in functioning and quality of life is common in people two months after compensable motor vehicle crashes: prospective cohort study. Inj Epidemiol. 2015;2(1):8.

12. Hazen A, Ehiri J E. Road traffic injuries: hidden epidemic in less developed countries. J Natl Med Assoc [Internet]. 2006 Jan;98(1):73-82. Available from: https://www.ncbi.nlm.nih.gov/pubmed/16532982

13. Gopinath B, Jagnoor J, Harris I A, Nicholas M, Casey P, Blyth F, et al. Health-related quality of life 24 months after sustaining a minor musculoskeletal injury in a road traffic crash: A prospective cohort study. Traffic Inj Prev. 2017 Apr;18(3):251-6.

14. Khati I, Hours M, Charnay P, Chossegros L, Tardy H, Nhac Vu H T, et al. Quality of life one year after a road accident: Results from the adult ESPARR cohort. J Trauma Acute Care Surg. 2013;74(1):301-11. 
15. Kaske S, Lefering R, Trentzsch H, Driessen A, Bouillon B, Maegele M, et al. Quality of life two years after severe trauma: A single centre evaluation. Vol. 45, Injury. 2014:100-5.

16. Kenardy J, Heron Delaney M, Warren J, Brown E. The effect of mental health on long-term health-related quality of life following a road traffic crash: Results from the UQ SuPPORT study. Injury. 2014 Nov 18; 46.

17. Gopinath B, Jagnoor J, Elbers N A, Cameron I D. Overview of findings from two year study of claimants who had sustained a mild or moderate injury in a road traffic crash: prospective study. BMC Research Notes . 2017;10.

18. Rissanen R, Berg H Y, Hasselberg M. Quality of life following road traffic injury: A systematic literature review. Accid Anal Prev. 2017;108:30820.

19. Mayou R, Bryant B. Consequences of road traffic accidents for different types of road user. Injury. 2003;34(3):197-202.

20. OECD Health Statistics 2014 Definitions, Sources and Methods [Internet]. Vol. 2008. Available from: https://ec.europa.eu/transport/road_safety/specialist/knowledge/pedestrians/crash_characteristics_where_and_how/data_considerations_en

21. EuroQol Group. EuroQol - a new facility for the measurement of health-related quality of life. Health Policy (New York). 1990;16(3):199-208.

22. Sadeghi Bazargani H, Aboubakri O, Asghari Jafarabadi M, Alizadeh Aghdam M B, Imani A, Tabrizi J, SalariLak S, et al. Psychometric properties of the short and ultra-short versions of socioeconomic status assessment tool for health studies in Iran (SES-Iran). J Clin Res Gov [Internet]. 2016;5(1). Available from: http://index.sciencepub.se/ojs/index.php/JCRG/article/view/185

23. Crowder M. Longitudinal Data Analysis edited by Garrett Fitzmaurice, Marie Davidian, Geert Verbeke, Geert Molenberghs. Int Stat Rev [Internet]. 2009 Apr 1;77(1):148-9. Available from: https://doi.org/10.1111/j.1751-5823.2009.00074_2.x

24. Bursac Z, Heath Gauss C, Williams D K, Hosmer D W. Purposeful selection of variables in logistic regression. Source Code Biol Med. 2008;3(17).

25. Mollon L, Bhattacharjee S. Health related quality of life among myocardial infarction survivors in the United States: A propensity score matched analysis. Health Qual Life Outcomes [Internet]. 2017;15(1):235. Available from: https://www.ncbi.nlm.nih.gov/pubmed/29202758

26. McCaffrey N, Kaambwa B, Currow D C, Ratcliffe J. Health-related quality of life measured using the EQ-5D-5L: South Australian population norms. Health Qual Life Outcomes. 2016;14(1):133.

27. Yao Q, Liu C, Zhang Y, Xu L. Changes in health-related quality of life of Chinese populations measured by the EQ-5D-3 L: a comparison of the 2008 and 2013 National Health Services Surveys. Health Qual Life Outcomes [Internet]. 2019;17(1):43. Available from: https://doi.org/10.1186/s12955-019-1109-x

28. Rezaei S, Hajizadeh M, Kazemi A, Khosravipour M, Khosravi F, Rezaeian S. Determinants of health-related quality of life in Iranian adults: evidence from a cross-sectional study. Epidemiol Health [Internet]. 2017;39:e2017038. Available from: https://www.ncbi.nlm.nih.gov/pubmed/28823119

29. Goniewicz K, Goniewicz M, Pawłowski W, Fiedor P. Road accident rates: strategies and programmes for improving road traffic safety. Eur J Trauma Emerg Surg. 2015 Jul 11;42.

30. World Health Organization. Global status report on road safety 2018. 20 Avenue Appia 1211 Geneva 27 Switzerland; 2018.

31. Marshall R D, Cárcamo J H, Blanco C, Liebowitz M. Trauma-focused psychotherapy after a trial of medication for chronic PTSD: pilot observations. Am J Psychother [Internet]. 2003 Jul 1;57(3):374-83. Available from: https://doi.org/10.1176/appi.psychotherapy.2003.57.3.374

32. Nhac Vu H T, Hours M, Charnay P, Chossegros L, Boisson D, Luauté J, et al. Predicting self-reported recovery one year after major road traffic accident trauma. J Rehabil Med. 2011;43(9):776-82.

33. Gopinath B, Harris I A, Nicholas M, Casey P, Blyth F, Maher C G, et al. A comparison of health outcomes in older versus younger adults following a road traffic crash injury: a cohort study. PLoS One [Internet]. 2015 Apr 1;10(4):e0122732-e0122732. Available from: https://www.ncbi.nlm.nih.gov/pubmed/25830702

34. Fitzharris M, Bowman D, Ludlow K. Factors associated with return-to-work and health outcomes among survivors of road crashes in Victoria. Aust N Z J Public Health. 2010;34(2):153-60.

35. Kenardy J, Heron Delaney M, Warren J, Brown E. The effect of mental health on long-term health-related quality of life following a road traffic crash: Results from the UQ SuPPORT study. Injury. 2015;46(5):883-90.

36. Srinivasa Kumar P V, Srinivasan K. A study on environmental factors influencing road traffic accident victims in district hospital, karimnagar. Int J Res Heal Sci. 2013;1(2).

37. Potoglou D, Carlucci F, Cirà A, Restaino M. Factors associated with urban non-fatal road-accident severity. Int J Inj Contr Saf Promot. 2018;25(3):303-10.

38. Afukaar F. Speed control in developing countries: issues, challenges and opportunities in reducing road traffic injuries. Inj Control Saf Promot. 2003 Apr 1;10:77-81.

39. Yu W Y, Chen C Y, Chiu W T, Lin M R. Effectiveness of different types of motorcycle helmets and effects of their improper use on head injuries. Int J Epidemiol. 2011 Mar 1;40:794-803. 
Tables

Page 9/13 


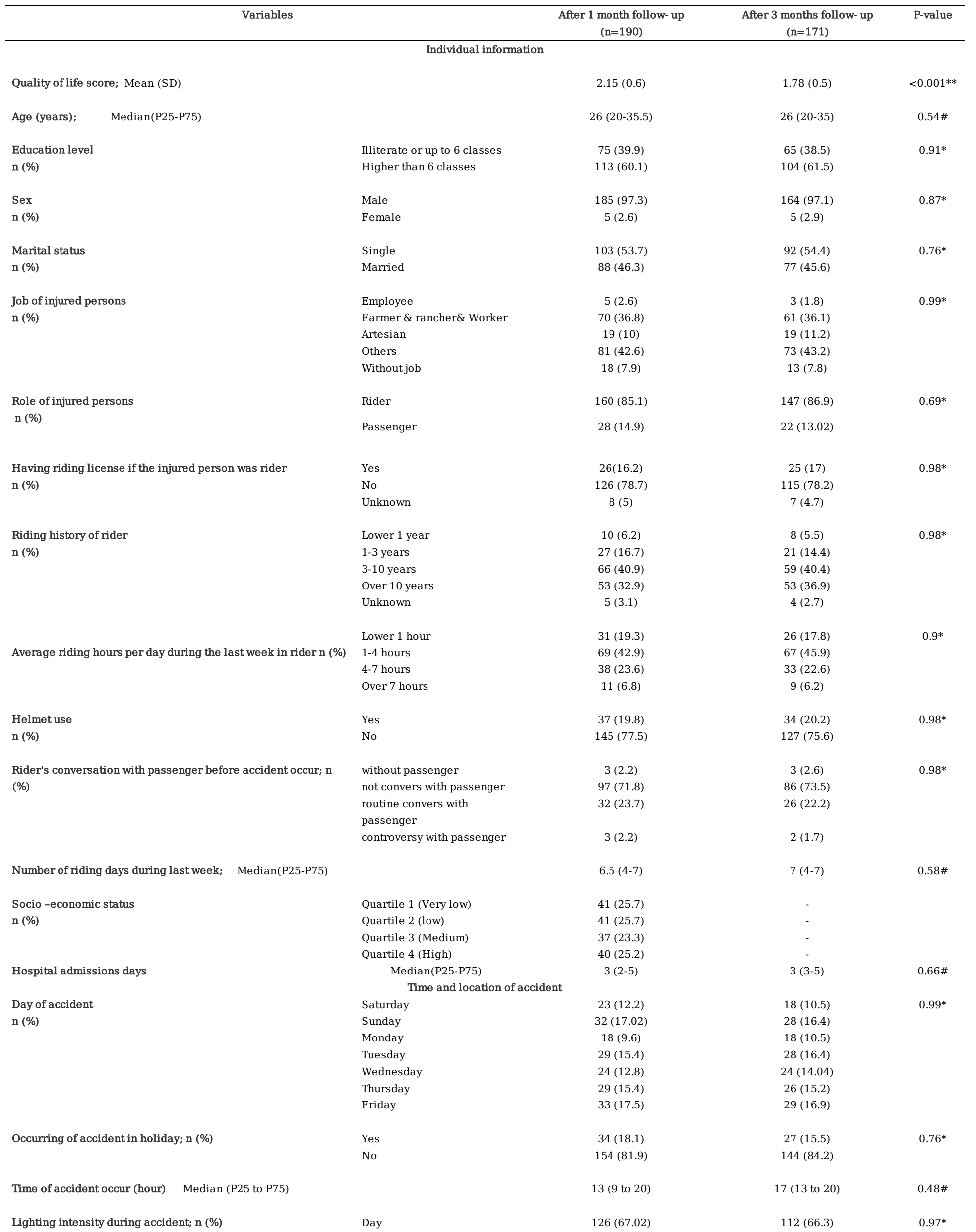


** P-value based on T independent test

\# P-value based on Mann-Whitney test

*P-value based on chi-square test

Page $11 / 13$ 


\begin{tabular}{|c|c|c|c|c|}
\hline \multicolumn{2}{|r|}{ Variables } & \multirow{2}{*}{$\begin{array}{l}\text { After } 1 \text { months follow - up } \\
(\mathrm{n}=190)\end{array}$} & \multirow{2}{*}{$\begin{array}{l}\text { After } 3 \text { months follow- up } \\
(\mathrm{n}=171)\end{array}$} & \multirow{2}{*}{$\begin{array}{c}\text { P- } \\
\text { *value } \\
0.78 *\end{array}$} \\
\hline Weather condition during accident; $\mathbf{n}$ & Sunny & & & \\
\hline (\%) & Cloudy & $8(4.3)$ & $5(2.9)$ & \\
\hline & Rainy & $7(3.7)$ & $7(4.1)$ & \\
\hline \multirow{2}{*}{$\begin{array}{l}\text { Slippery condition during accident; } n \\
\text { (\%) }\end{array}$} & Dry & $174(92.5)$ & 159 (92.9) & $0.96 *$ \\
\hline & Slippery & $11(5.8)$ & $9(5.3)$ & \\
\hline \multirow{2}{*}{$\begin{array}{l}\text { Occur of accident in residential zone; } \mathrm{n} \\
\text { (\%) }\end{array}$} & Yes & $119(63.3)$ & $104(60.8)$ & $0.96 *$ \\
\hline & No & $68(36.2)$ & $66(38.6)$ & \\
\hline & ses & & & \\
\hline \multirow[t]{2}{*}{ Intercity accidents; $\mathbf{n}(\%)$} & Main road & 97 (90.9) & $86(89.6)$ & $0.83 *$ \\
\hline & Byroad & $10(9.3)$ & $10(10.4)$ & \\
\hline \multirow[t]{2}{*}{ Outer city accidents; $\mathbf{n}(\%)$} & Main road & $21(25.9)$ & $22(29.3)$ & $0.97 *$ \\
\hline & Byroad & 59 (72.8) & $52(69.3)$ & \\
\hline & Vehicle information & & & \\
\hline \multirow{2}{*}{$\begin{array}{l}\text { Number of vehicle involved in } \\
\text { accidents; } \mathrm{n}(\%)\end{array}$} & Single vehicle & $44(23.4)$ & $43(25.2)$ & $0.88^{*}$ \\
\hline & Multivehicle & $141(75)$ & $126(73.7)$ & \\
\hline \multirow{3}{*}{$\begin{array}{l}\text { Type of vehicle engage; } \\
\text { n (\%) }\end{array}$} & Don't have vehicle & $44(23.4)$ & $42(24.6)$ & $0.96^{*}$ \\
\hline & Others (Bicycle, Motorcycle, bus, heavy car) & $32(17.02)$ & $26(15.2)$ & \\
\hline & Car & $112(59.6)$ & $103(60.2)$ & \\
\hline \multirow{4}{*}{$\begin{array}{l}\text { Mechanism of accidents; } \\
\text { n (\%) }\end{array}$} & Vehicle-Fixed object & $11(5.8)$ & $10(5.8)$ & $0.99 *$ \\
\hline & Vehicle-vehicle & 139 (73.9) & $124(72.5)$ & \\
\hline & Overturning & $23(12.2)$ & $23(13.4)$ & \\
\hline & $\begin{array}{l}\text { Others(vehicle-pedestrian, vehicle-animal, falling, Exit from } \\
\text { the road) }\end{array}$ & $11(5.8)$ & $11(6.4)$ & \\
\hline & Type of injuries & & & \\
\hline \multirow[t]{2}{*}{ Head injury; n (\%) } & Yes & $52(27.7)$ & $41(23.9)$ & $0.57 *$ \\
\hline & No & $136(72.3)$ & $130(76.02)$ & \\
\hline \multirow[t]{2}{*}{ Thorax injury; n (\%) } & Yes & $12(6.4)$ & $11(6.4)$ & $0.98 *$ \\
\hline & No & $176(93.6)$ & 160 (93.6) & \\
\hline \multirow[t]{2}{*}{ Neck injury; n (\%) } & Yes & $4(2.1)$ & $4(2.3)$ & $0.82^{*}$ \\
\hline & No & $184(97.9)$ & 167 (97.6) & \\
\hline \multirow[t]{2}{*}{ Shoulder and upper arm injuries; $n$ (\%) } & Yes & $18(9.6)$ & $18(11.1)$ & $0.4^{*}$ \\
\hline & No & $170(90.4)$ & $153(88.9)$ & \\
\hline \multirow[t]{2}{*}{ Elbow and forearm injuries; $\mathrm{n}(\%)$} & Yes & $19(10.1)$ & $19 \quad(11.1)$ & $0.75^{*}$ \\
\hline & No & 169 (89.9) & $152(88.9)$ & \\
\hline \multirow[t]{2}{*}{ Wrist and hand injuries; $\mathbf{n}(\%)$} & Yes & $11(5.8)$ & $11(6.4)$ & $0.38^{*}$ \\
\hline & No & $177(94.1)$ & 157 (93.6) & \\
\hline \multirow[t]{2}{*}{ Hip and thigh injuries; $n(\%)$} & Yes & $27(14.4)$ & $26(15.2)$ & $0.82 *$ \\
\hline & No & $161(85.6)$ & $145(84.8)$ & \\
\hline \multirow[t]{2}{*}{ Knee and lower leg injuries; n (\%) } & Yes & $69(36.7)$ & $59(34.5)$ & $0.66^{*}$ \\
\hline & No & $119(63.3)$ & $112(65.5)$ & \\
\hline \multirow[t]{2}{*}{ Ankle and foot injuries; $n(\%)$} & Yes & $15(7.9)$ & $12(7.02)$ & $0.73^{*}$ \\
\hline & No & $173(92.02)$ & 159 (92.9) & \\
\hline Abdomen \& lower back \& & Yes & $20(10.6)$ & $18(10.5)$ & $0.97 *$ \\
\hline $\begin{array}{l}\text { lumbar \& spine \& } \\
\text { pelvis injuries; n (\%) }\end{array}$ & No & $168(89.4)$ & 153 (89.5) & \\
\hline
\end{tabular}

*P-value based on chi-square test 
Table 2. Multivariable Generalized Estimating Equations (GEE) analysis of the quality of life score in motorcycle traffic injuries

\begin{tabular}{|c|c|c|c|c|}
\hline \multicolumn{2}{|l|}{ variables } & \multicolumn{3}{|c|}{ Multivariable GEE } \\
\hline & & B & 95\% Confidence. Interval & P-value \\
\hline \multirow[t]{2}{*}{ Role of injured persons } & Rider & Ref & Ref & Ref \\
\hline & Passenger & -0.14 & $(-0.31,0.03)$ & 0.11 \\
\hline \multirow[t]{2}{*}{ Hip and thigh injuries } & Yes & 0.26 & $(0.10,0.42)$ & 0.001 \\
\hline & No & Ref & Ref & Ref \\
\hline \multirow[t]{2}{*}{ Knee and lower leg injuries } & Yes & 0.29 & $(0.16,0.42)$ & 0.001 \\
\hline & No & Ref & Ref & Ref \\
\hline \multirow[t]{2}{*}{ Number of vehicles involved in accident } & single vehicle & -0.26 & $(-0.43,-0.09)$ & 0.04 \\
\hline & Multivehicle & Ref & Ref & Ref \\
\hline \multirow[t]{2}{*}{ Weather condition during accident } & No rainy & Ref & Ref & Ref \\
\hline & Rainy & 0.33 & $(0.12,0.53)$ & 0.001 \\
\hline
\end{tabular}

\section{Figures}

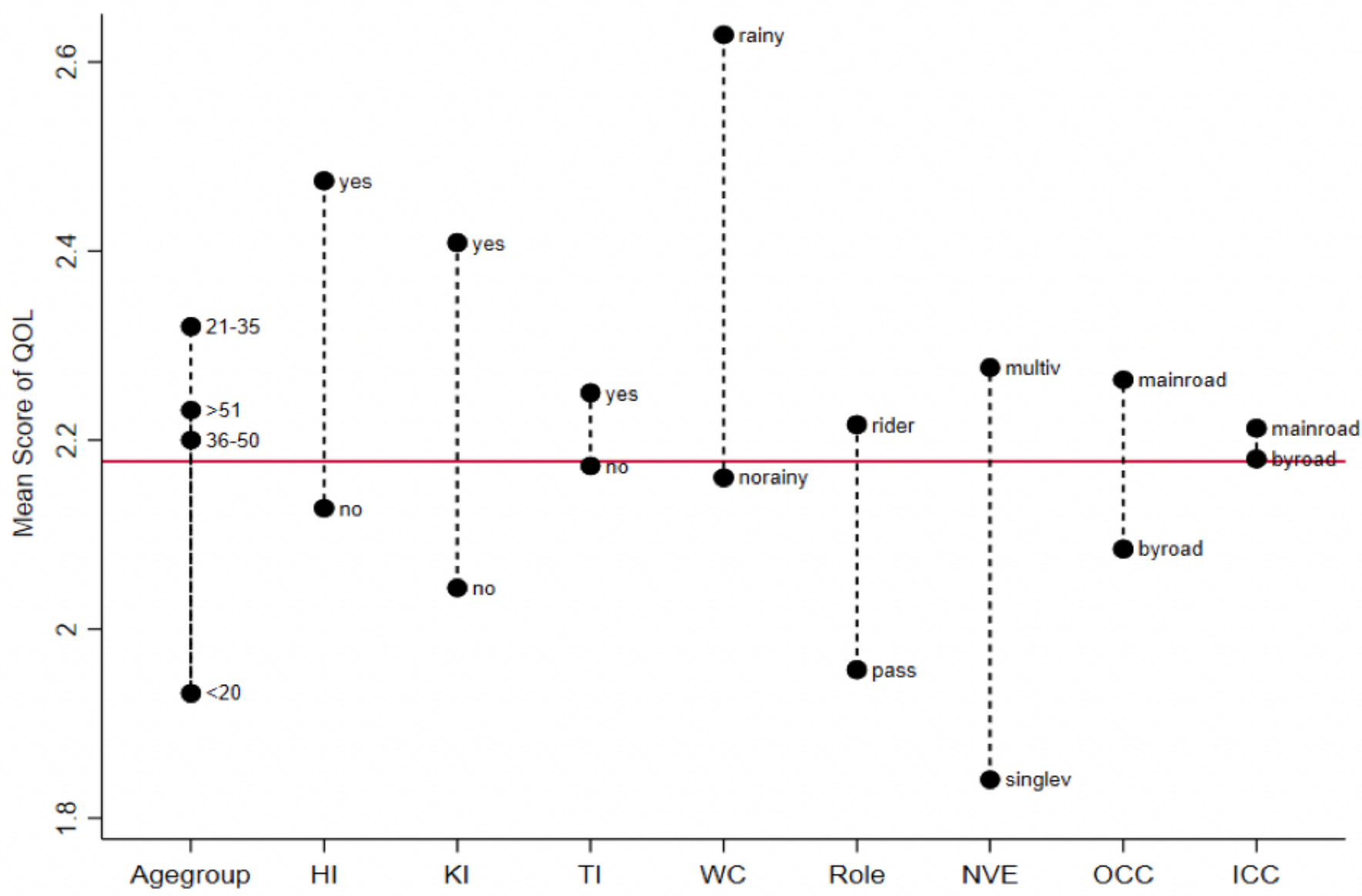

Figure 1

Distribution of mean score of QOL one month after motorcycle traffic injuries among age groups, $\mathrm{HI}$ (Hip Injury), $\mathrm{KI}$ (Knee Injury), TI (Thorax Injury), WC (Weather Condition during accident), Role of injured persons (rider, passenger), VNE (Number of Vehicle Engaged), multiv (multivehicle), singlev (single vehicle), OCC (Outer city crashes), ICC (Intercity crashes). 